\title{
Barley malt-based composition as a galactagogue a randomized, controlled trial in preterm mothers
}

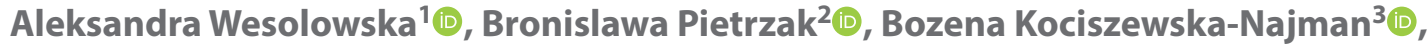 \\ Miroslaw Wielgos $^{2} \mathbb{D}$, Krzysztof Czajkowski ${ }^{4} \mathbb{D}$, Ewa Wietrak ${ }^{5}$, Katarzyna Karzel ${ }^{6}$, \\ Maria K. Borszewska-Kornacka? \\ ${ }^{1}$ Laboratory of Human Milk and Lactation Research at Regional Human Milk Bank in Holy Family Hospital, \\ Medical University of Warsaw, Department of Neonatology, Warsaw, Poland \\ ${ }_{2}^{2} 7^{\text {st }}$ Department of Obstetrics and Gynecology, Faculty of Medicine, Medical University of Warsaw, Poland \\ ${ }^{3}$ Department of Neonatology, Faculty of Health Sciences, Medical University of Warsaw, Poland \\ ${ }^{4} 2^{\text {nd }}$ Department of Obstetrics and Gynecology, Warsaw Medical University, Warsaw, Poland \\ ${ }^{5} R \& D$ Nutropharma LIc, Warsaw, Poland \\ ${ }^{6}$ University of Warsaw, Faculty of Psychology, Warsaw, Poland \\ ${ }^{7}$ Department of Neonatology and Intensive Care Unit, Faculty of Medicine, Medical University of Warsaw, Poland
}

\begin{abstract}
Objectives: Delayed or insufficient breast milk production, as well as low milk supply, is still a challenging problem to overcome, particularly in the case of preterm delivery. Herbal galactagogues might be a good way to increase milk supply, however, there is a lack of clinical studies confirming their efficacy and safety.

The aim of this study was to verify the safety and effectiveness as a galactagogue of the unique galactagogue composition based on barley malt with $\beta$-glucan and lemon balm.

Material and methods: The study included 117 mothers of preterm infants randomly divided into the Galactagogue Group given galactagogue and the Placebo Group. A complete data set was obtained for 80 participants, divided equally between two groups.

Volume of milk expressed by mothers during the first two weeks after delivery was the primary outcome and safety of the product was the secondary outcome.

Results: Volume of milk recorded on participants' last visit in the Galactagogue Group was significantly higher than in the Placebo Group ( $95 \mathrm{~mL}$ vs $62.5 \mathrm{~mL}, \mathrm{p}=0.049$ ). The total expressed milk volume during the study was $4209 \pm 335 \mathrm{~mL}$ in the Placebo Group vs $6036 \pm 498 \mathrm{~mL}(p=0.003)$ in the Galactagogue Group.

Conclusions: Supplementation with unique Galactagogue composition was safe and increased milk output which allowed achieving target minimal volume of $500 \mathrm{~mL}$ per day in first week of lactation in preterm mothers.
\end{abstract}

Key words: barley malt; galactagogue; insufficient milk supply; preterm baby; human milk

Ginekologia Polska 2021; 92, 2: 118-125

\section{INTRODUCTION}

Lactogenesis in humans is a very complicated process. It depends not only on reproductive and metabolic hormones but is self-regulated through the autocrine-paracrine mechanism. Additionally, both physical and emotional factors are involved in successful onset of milk production [1-4]. The fall of progesterone after delivery, followed by increase in prolactin (PRL) levels triggers the beginning of lactogenesis II, a period of copious milk secretion. However, there is no direct correlation between baseline PRL levels and volume of expressed milk [5]. Milk volume depends mostly on frequency and duration of breastfeeding/pumping throughout early lactation period [5].

Delayed or insufficient breast milk production, as well as low milk supply, is still a challenging problem to overcome, particularly in the case of preterm delivery [6-8] which results in lower basal PRL levels compared with mothers who give birth at term [9]. The other non-physiological causes of 
lactational failure are complex and include separation from the newborn after delivery, poor maternal psychological well-being and health after an unexpected delivery [10-13].

For vulnerable preterm infants, a mother's own milk is more a medicine than nutrition. The mother's milk intake is increasingly recognized as a key variable associated with positive clinical outcomes in preterm infants [14-16]. Therefore, it is reasonable to seek new, natural substances which act as a galactagogues) initiating and augmenting the secretion of mother's milk [17]. Unfortunately, earlier studies with herbal based galactagogues have not been well-designed because of a lack of randomization, controls or blinding and with poor evidence regarding the efficacy and safety [18-20]. A good candidate for natural and safe galactagogue may be ß-glucan present in barley malt.

Barley malt is produced from the malting process where grains are allowed to germinate and then quickly dried. As a result of malting, bioactive components including those that potentially increase milk supply, are released from barley grain [21]. In fact, non-alcoholic beer is used traditionally by mothers in many cultures during lactation to increase milk supply although its prolactogenic mechanism has not been fully clarified with a clinical study $[22,23]$.

Studies based on animal models suggests that a polysaccharide such as $\beta$-glucan found in barley enables milk production by prolactin dependent mechanisms after intravenous injection [24, 25]. An observational study was conducted in group of 128 mothers with insufficient milk supply who consumed barley malt-based product for 14 days [26]. Certified lactation consultants evaluated time of effective sucking and other factors responsible for a successful lactation. Regular breast milk swallowing was elongated in 91\% of babies and the amount of milk pumped by mothers increased more than twice [26]. Therefore, the beneficial effect of the formulation based on barley malt with $\beta$-glucan and lemon balm (Galactogogue) was investigated further in the group of mothers who gave birth prematurely and were vulnerable to lactation failure.

\section{Objectives}

The aim of this double-blind, randomized, placebo controlled study was to investigate efficacy in increasing milk production and safety of use of unique galactagogue composition.

\section{MATERIAL AND METHODS}

\section{Settings and Participants}

This study was conducted at two NICUs associated with the Medical University of Warsaw between April 2014 and October 2015 with approval of the Ethics Committee in the Medical University of Warsaw (number KB 40/2014). The target population consisted of women above 18 years old who delivered infants $<37$ weeks gestation (gestational age confirmed according to the last menstrual period) and gave written informed consent to participate in the study.

Participants were eligible for the study if they were available to be enrolled within two days following birth, declaredelectric breast pump use (at least 6 times a day, including night) and agreed on filling up the lactation diary which allowed to monitor the increase in expressed milk volume through the progress of establishing and maintaining lactation. Women were considered ineligible if they were diagnosed with hypothyroidism or either type 1 or 2 diabetes before pregnancy and were receiving treatment. Moreover, participants already participating in another clinical trial were excluded.

This RCT was retrospectively registered on ClinicalTrials.gov on November $14^{\text {th }}, 2017$ under the identification number NCT03341481.

\section{Study Design}

This clinical trial was double-blind, randomized, and placebo-controlled, conducted according to the Good Clinical Practice, including monitoring by a qualified Clinical Research Associate. One Hundred Seventeen mothers who gave birth prematurely were enrolled in the study within 48 hours postpartum and were randomly assigned to the two study groups (Placebo Group or Galactagogue Group). The concealed allocation sequence was generated by central randomization using a computer software program. Femaltiker ${ }^{\circledR}$ a proprietary, commercially available product produced by Nutropharma Llc., was used as the galactagogue in the Galactagogue Group. Femaltiker ${ }^{\circledast}$ containing composition was notified at the Polish Chief Sanitary Inspectorate as food for special medical purposes. Femaltiker formula consists of powdered lemon balm leaves (Melissa officinalis L.); barley malt (Hordeum vulgare Linn) enriched with $70 \%$ barley-glucan. Other inactive ingredients included sucrose and natural caramel flavoring. The composition is protected by patent nr. 229569, therefore the exact amount of each component was not disclosed. The placebo was produced as a blend of sucrose, apple fiber and natural aroma caramel and was in the same package as Femaltker ${ }^{\circledast}$. The products were indistinguishable by color, taste and texture. Each subject received 28 packages to take twice daily for 14 days during the study. Participants were asked to return the empty packages during their check-up for compliance monitoring. Participants and medical staff were blinded to which package contained the active product until the end of the trial.

According to the study scheme mothers had to have undergone three hospital visits during the first two weeks postpartum. The first visit occurred as soon as possible, following delivery but no later than on the second day ( \pm 1 day) post-delivery. The second visit occurred at the end of the first week of lactation at day six and the third visit was 
on day 14 ( \pm 2 days) postpartum. Mothers were instructed to pump their breasts every four hours (six times per day for 10-15 minutes per breast) using a standardized electric breast pump. A Symphony ${ }^{\circledR}$ PLUS ${ }^{T M}$ Breast Pump, Medela, Switzerland was used in the hospital and a Lactina Electric ${ }^{\circledR}$ PLUS ${ }^{\mathrm{TM}}$ Medela, Switzerland was available for home use.

\section{Primary and secondary outcomes}

The primary outcome was the total volume of milk expressed by participants from the second to the $14^{\text {th }}$ postnatal day. Secondary outcome was the safety of the intervention.

\section{Data collection}

Clinical data of mothers and infants at delivery and throughout study duration were collected including maternal and infant demographics, prior breastfeeding experience, colostrum expression after delivery and ability to latch onto the breast.

\section{Milk production data}

Participants recorded daily lactation information during the study including exact volume of milk in $\mathrm{mL}$ expressed at each expression session, the exact time of each milk expression session, the total milk expression time per day, the total amount of milk expressed per day, and the longest interval between expression sessions in a standardized lactation diary. Information concerning self-estimation of the onset of lactogenesis stage II was provided by participants marking the applicable answer in the lactation diary (feeling of full/empty breasts, swollen, painful, tender). The lactation diary and lactation equipment including Medela's $150 \mathrm{~mL}$ disposable bottles were provided to participants at the study enrollment.

Daily volume of milk produced was confirmed by the medical staff by summation of all recorded milk volumes during a 24-hour period prior each of hospital visits. Furthermore, the amount of milk expressed in a single session during each hospital visit on days 2 (+/1 day), 6, 14 (+/2 days) postpartum was measured using Medela's $150 \mathrm{~mL}$ disposable bottles by the lactation consultant.

\section{Safety data}

Possible side effects of the intervention were monitored at each visit by a member of the clinical team. It included skin examination and collecting information from subjects concerning digestive symptoms such as nausea, a bad taste in the mouth, and pain. If side effects occurred, they were assessed by completing a rating scale of adverse symptoms intensity (mild, moderate, severe).

\section{Data analysis and statistical tests}

Data analysis included only those subjects who completed the study per protocol.
Study sample was calculated based on previous research. It was assumed that the standard deviation (SD) of the mean milk production in the second week of lactation is approximately $160 \mathrm{~mL} /$ day [27]. Therefore, we expected a SD of total breast milk volume of about $2500 \mathrm{~mL}$ within the first 14 days postpartum. Under further assumptions of statistical significance level of $p<0.5$ and power of 0.8 , we calculated that with a sample size of 40 participants per group it would be possible to assess (using standard t-test) a difference between study groups of size $1585 \mathrm{~mL}$ as statistically significant. A full data set was obtained for 80 participants, divided equally between the two study groups. The data was imported into SPSS for Windows for further analysis.

Student t-test for independent sample was used to analyze demographic variables including mother's age at the time of delivery, duration of pregnancy (in multiple pregnancies), infant gestational age and birth weight. They were compared using $95 \%$ confidence intervals for means with standard error (SE).

Moreover, maternal factors related to pregnancy and postnatal care were compared using $\mathrm{x} 2$ testing. Student t-test was used to compare lactation stimulation parameters as total volume of expressed milk, total time of expressing, number of expression sessions between groups. There were showed using $95 \%$ confidence intervals for means with SE. Difference in daily volume of milk in the following days was presented using $95 \%$ confidence intervals for means with SE. Volume of milk from day 4 to 11 depending on the study group was analyzed by variance analysis (ANOVA). The daily volume of expressed milk was only analyzed for the time in which all 80 subjects participated in the study (to the $11^{\text {th }}$ day postpartum) and the volume of expressed milk was measurable in $\mathrm{mL}$ (volume $\geq 1 \mathrm{~mL}$ from $4^{\text {th }}$ day postpartum).

Additionally, covariance analysis (ANCOVA) was performed with Placebo Group vs Galactagogue Group as grouping variable and number of the sessions during the day as a covariant.

A p-value of $<.05$ was considered statistically significant, $p<.01$ was considered highly significant.

\section{RESULTS}

One hundred seventeen mothers of preterm infants were randomized with 59 allocated to the placebo and 58 to the Galactagogue group. Four participants from each group did not receive the intervention. Reasons for not receiving the intervention, loss to follow-up and exclusion from analysis are listed on Figure 1. Complete data was obtained for 40 participants in each arm.

There was no statistically significant difference between participants in terms of demographic characteristics. In addition, there were no statistically significant differ- 


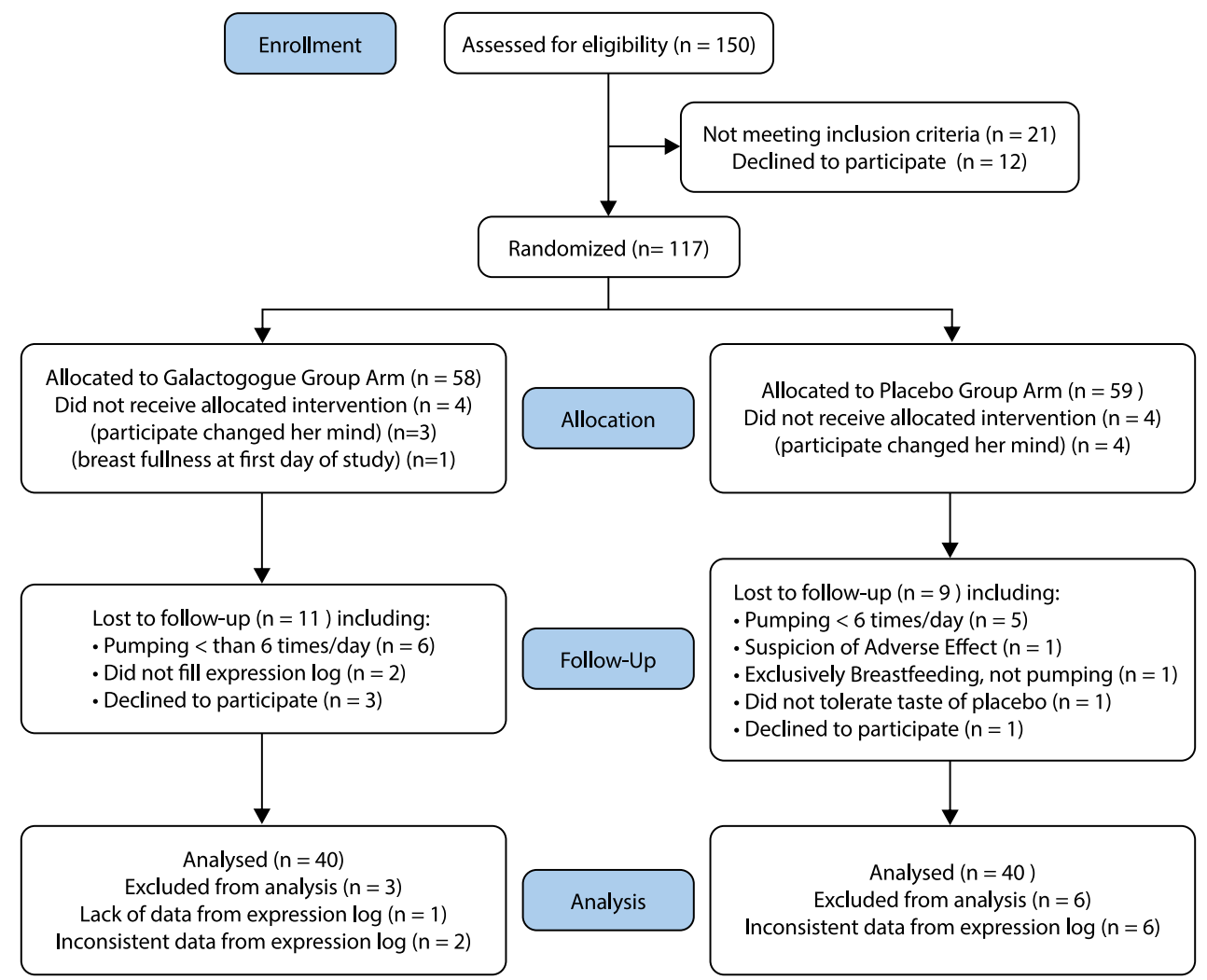

Figure 1. Flow Chart of Study; The blue boxes show the progress through the phases of a parallel randomized trial of two groups: Galactagogue and Placebo. Numbers in white boxes ( $n$ ) show the subjects excluded, withdrawn from the study, patients that dropped off and number of subjects taken for analysis

Table 1. Mothers $(n=80)$ and infants $(n=114)$ characteristics at randomization

\begin{tabular}{|c|c|c|c|c|c|c|}
\hline \multirow{2}{*}{ Mothers } & \multicolumn{2}{|c|}{ Placebo group $(n=40)$} & \multicolumn{2}{|c|}{ Galactagogue group $(n=40)$} & \multirow{2}{*}{$\mathbf{t}$} & \multirow{2}{*}{$\mathbf{p}$} \\
\hline & $\mathrm{M} \pm \mathrm{SE}$ & $95 \% \mathrm{Cl}$ & $M \pm S E$ & $95 \% \mathrm{Cl}$ & & \\
\hline Age [years] & $31.6 \pm 0.8$ & $30.0-33.1$ & $30.9 \pm 0.8$ & $29.3-32.5$ & 0.63 & 0.53 \\
\hline Pregnancy week at birth & $31.5 \pm 0.4$ & $30.6-32.4$ & $31.5 \pm 0.5$ & $30.4-32.8$ & 0.00 & 1.00 \\
\hline \multirow{2}{*}{ Infants } & \multicolumn{2}{|c|}{ Placebo Group $(n=56)$} & \multicolumn{2}{|c|}{ Galactagogue Group ( $n=58$ ) } & \multirow{2}{*}{$\mathbf{t}$} & \multirow{2}{*}{$\mathbf{p}$} \\
\hline & $M \pm S E$ & $95 \% \mathrm{Cl}$ & $M \pm S E$ & $95 \% \mathrm{Cl}$ & & \\
\hline Birth weight & $1719 \pm 100$ & $1553-1885$ & $1745 \pm 92$ & 1589-1900 & 0.19 & 0.85 \\
\hline Gestational age [weeks] & $31.4 \pm 0.4$ & $30.7-32.2$ & $31.8 \pm 0.5$ & $31.0-32.7$ & 0.60 & 0.55 \\
\hline
\end{tabular}

Demographics of participants in analyzed sample $n$ (80) of mothers and infants $n$ (114); The difference with $p$ value $<0.05$ is considered statistically significant; $M$ - mean; $\mathrm{SE}$ - standard error; $\mathrm{Cl}$ - confidence interval

ences in their infant's birth weight or gestational age (Tab. 1). Finally, there was no significant difference in pregnancy and postnatal care in both groups. Participants were mostly primiparas that gave singleton birth through caesarian section with no previous breastfeeding experience (data not shown). Colostrum expression was possible in 39 women (97.5\%) from Placebo Group and 37 women (92.5\%) in the Galactagogue Group ( $x 2=1.05 ; p=0.30$ ). Due to premature birth a low number of neonates were able to latch on instantly 5 (12.5\%) in the Placebo Group and 7 (17.5\%) in the Galactagogue Group; $\chi^{2}=0.32 ; p=0.53$ ).

\section{Milk production data}

Volume of milk expressed during the three hospital visits is presented as the median with $95 \% \mathrm{Cl}$ in Figure 2. Volume expressed during the third visit (day 14) was statistically significantly higher in mothers who received Galactagogue compared to the Placebo Group ( $62.5 \mathrm{~mL}$ vs $95 \mathrm{~mL} ; Z=2.40$, $p=0.01$, with Bonferrroni correction $p=0.049$ ).

Total volume of milk recorded in the lactation diaries over the entire study from day 2 to 14 was statistically significantly higher in the group receiving Galactagogue (6036 mL \pm 498 vs $4209 \mathrm{~mL} \pm 335 ; \mathrm{p}=0.003$ ). There were 
no differences in the total expression time $(p=0.68)$ and number of milk expression sessions $(p=0.27)$ between the study groups (Tab. 2). Despite the exemptions from the protocol regarding the interval between follow-up visits in case of four participants, the mean period of participation in the study did not differ between groups $(p=0.40)$ (Tab. 2).

Comparison of the average daily volume of milk expressed revealed that the Galactagogue Group expressed statistically more milk already on day seven of the study $(p=0.01)$. The Placebo Group failed to reach $500 \mathrm{~mL}$ of expressed milk per day throughout whole study period (Fig. 3, Tab. 3).

A statistically significant effect of the group was found on daily volume of milk $(F=5.91, p=0.017)$. The daily volume of milk was statistically significantly higher in the Galactagogue Group throughout the study period in comparison to the Placebo Group. Only on 4 day $(p=0.13)$ and 6 day $(p=0.05)$ of the study the results failed to show statistical significance (Tab. 3).

The analysis with a number of milk expressing sessions during particular day as a covariant has shown differences in daily milk volume between the study groups. In the Galac-

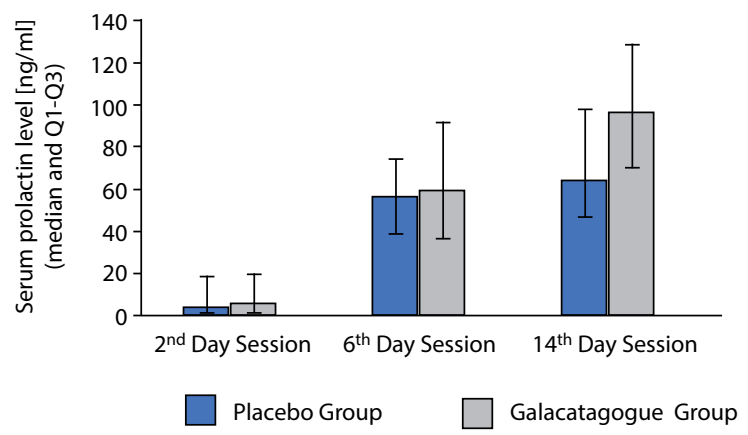

Figure 2. The volume of expressed mother's milk recorded at the hospital visit; The median milk volume expressed by women in the study groups (blue - placebo group, dark grey - galactagogue group) in the subsequent three measurement sessions at the hospital visit. The error bars represent $95 \% \mathrm{Cl}$. The asterisks indicate result that differ statistically significantly with $\mathrm{p}$-value $<0.05$ tagogue Group on days from 7 to 11 of the study there was statistically significantly ( $p<0.05$ for group factor) higher milk production in comparison to the Placebo Group (Tab. 4). On Days 9 and 10 the daily number of sessions had shown significant influence on the milk production in the study groups ( $p=0.009$ and $p=0.04$, respectively). This factor (daily number of sessions) has been included in the results and despite it the experimental group still obtained higher results for milk volume than the Placebo Group (Tab. 4).

\section{Safety data}

During the verbal assessment of intervention safety, two affirmative answers were noted in the placebo group, one was qualified as a serious side effect (SAE) not related to the product taken. Reported dryness of the skin was assumed to be related to iatrogenic hyperchloremia caused by administrated intravenous fluids and the participant was withdrawn from the study. There were no side effects reported in the group receiving Galactagogue. The product was well tolerated and consumed as a drink by a majority of the participants. One subject in the Placebo group reported the compound tasted bad and was withdrawn from the study.

\section{DISCUSSION}

This study suggests that Galactagogue which is composed of barley malt, $\beta$-glucan and lemon balm can serve as a galactagogue in mothers of preterm infants who struggle with insufficient milk production. Our study revealed that dietary intervention supplementation with food for special medical purposes Femaltiker ${ }^{\circledR}$ during the first two weeks of lactation increased milk volume in mothers of premature infants. Compared to the Placebo Group, mothers who received the Galactagogue composition produced $34 \%$ more milk during session on day 14 of lactation. Data obtained from the lactation diaries were consistent with data obtained by lactation consultations at the hospital. The Galactagogue Group produced 30\% more milk during the whole study period that was taken into the consideration for statistical analyses (from day 2 to 14 of the study).

Table 2. Total volume of expressed milk, total time of expressing and total number of expression sessions, duration of the study $(n=80)$

\begin{tabular}{|c|c|c|c|c|c|c|}
\hline & \multicolumn{2}{|c|}{ Placebo group $(n=40)$} & \multicolumn{2}{|c|}{ Galactagogue group $(n=40)$} & \multirow{2}{*}{$\mathbf{t}$} & \multirow{2}{*}{$\mathbf{p}$} \\
\hline & $\mathbf{M} \pm \mathrm{SE}$ & $95 \% \mathrm{Cl}$ & $\mathrm{M} \pm \mathrm{SE}$ & $95 \% \mathrm{Cl}$ & & \\
\hline $\begin{array}{l}\text { The volume of expressed } \\
\text { breastmilk [mL] }\end{array}$ & $4209 \pm 335$ & $3531-4886$ & $6036 \pm 498$ & $5029-7043$ & 3.04 & 0.003 \\
\hline Total expression time [min] & $2211 \pm 114$ & $1980-2442$ & $2280 \pm 123$ & $2031-2530$ & 0.41 & 0.68 \\
\hline $\begin{array}{l}\text { Number of expression } \\
\text { sessions [n] }\end{array}$ & $82 \pm 2$ & $78-86$ & $85 \pm 2$ & $81-90$ & 1.11 & 0.27 \\
\hline Duration of the study [days] & $12 \pm 0.2$ & $11.3-12.2$ & $12 \pm 0.2$ & $11.6-12.3$ & 0.84 & 0.40 \\
\hline
\end{tabular}

Indicators related to stimulation of lactation for analyzed sample $(n=80)$; The difference with $p$ value $<0.05$ is considered statistically significant; $M-$ mean; $S E-$ standard error; $\mathrm{Cl}$-confidence interval 


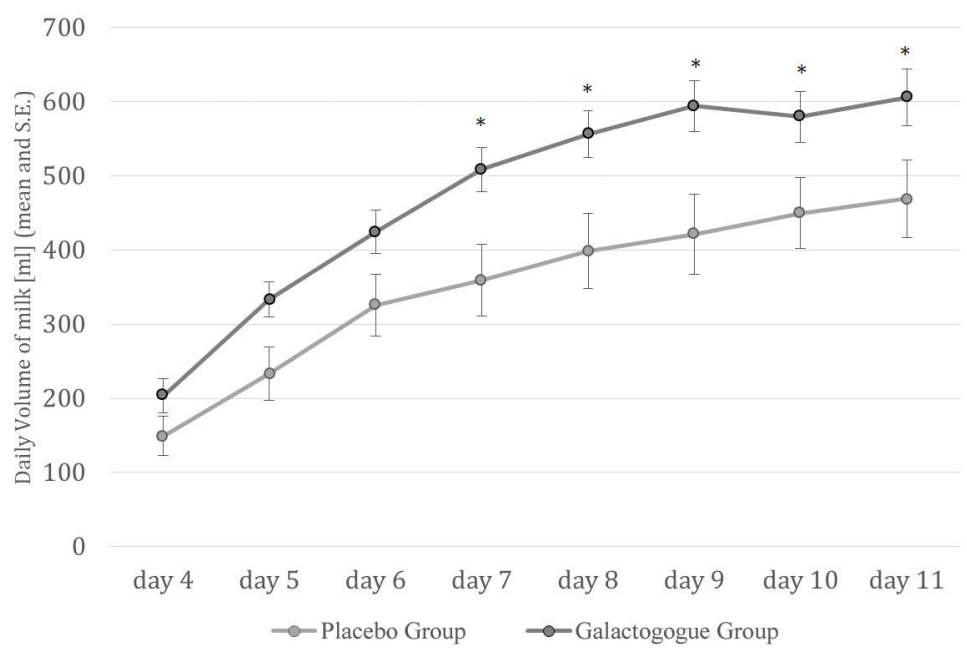

Figure 3. The average daily volume of mother's milk expressed by participants in the course of study; Mean milk volume expressed from day 4 to 11 in the Galactagogue Group (dark grey line) and the Placebo Group (light grey line). The error bars represent Standard Error (SE), The asterisks indicate result that differ statistically significantly with $p$-value $<0.05$

Increases in milk volume were not associated with maternal factors, postnatal care, or lactation practices recognized as supportive to milk supply in mothers of preterm infants.

Perceived and real insufficient milk supply is the most common reason for formula introduction in the early neonatal period $[28,29]$. It is especially harmful for preterm infants for whom mother's milk is crucial for their development and health [30, 31]. Unfortunately, mothers of preterm infants are at high risk of breastfeeding difficulties and the reasons for this are complex [32]. Often, regular milk expression, family support and medical advice including lactation consultation fail to resolve the problem [10, 15, 33] and maternal treatment to increase milk supply may be important. It is noteworthy that in Poland drugs such as domperidone and metoclopramide, that have proven efficacy in increasing milk production are not authorized for this indication, therefore their use is treated as off- label use [17] and is rather marginal. Other popular herbal galactagogues such as fenugreek and silymarin from milk thistle (Silybum marianum) does not have strong and consistent scientific evidence in milk increase [17]. Fenugreek should be used with caution due to its unclear safety profile and very mild effect on milk production in studies with likely a placebo effect [17, 34].

One of the first randomized controlled trial (RCT) aimed to evaluate the efficacy of silymarin in mothers of preterm infants did not show statistically significant differences in milk production. When the formulation was improved by adding components to increase absorption, lactogenic effects were observed in the first month of lactation which continued over the first 3 months $[35,36]$. The total average milk volume observed in both groups by Zecca et al. [35], $(4136 \pm 4093 \mathrm{~mL}$ in the placebo vs $6523 \pm 5298 \mathrm{~mL}$ in the experimental, $\mathrm{p}<0.02)$ was comparable to our study $(4208.8 \pm 335.04 \mathrm{~mL}$, in the Placebo Group vs $6035.9 \pm 497.80$ in Galactagogue Group, $p=0.0033$ ). However, in our study the result spread between the patients was less by order of magnitude and intervention time was two times shorter ( 30 days of supplementation versus 14 days).

It is noteworthy that mothers in the experimental group in our study achieved an average daily expressed volume of milk of more than $500 \mathrm{~mL} / \mathrm{d}$ on day seven in comparison to the Placebo Group where this amount of milk was not achieved even at the last day of the study (Fig. 3, Tab. 3). As was shown earlier milk volume in the early stage of lactation is a predictor of successful milk production after very preterm birth [11,37]. Evidence indicates that the first 14 days is a critical period for coming into the volume. Milk supply greater than $500 \mathrm{~mL} / \mathrm{d}$ is a predictor of infants receiving maternal milk at discharge [33, 38].

To reflect the demands of a breastfed term baby recommendation for expression frequency is 8-12 times per day including during the night $[39,40,41]$. However, this frequency is not always achieved which may affect the quantity of milk produced [42]. Our study revealed that the overall mean number of daily expression sessions was seven times per day. Because expression frequency can impact milk production, daily volume of milk from day 7 to 11 were controlled for number of expression sessions in consecutive days by covariance analysis. Even though differences in milk expression frequency were observed between groups in selected study days (days 9 and 10), the daily volume of milk in the Galactagogue Group was still statistically significantly higher from day 7 to day 11 in comparison to the Placebo Group (Tab. 4).

Barley malt-based product was mentioned as a lactation stimulant and included as a part of lactation consultation scheme in case of insufficient milk supply [43]. The Expert's 


\begin{tabular}{|c|c|c|c|c|c|c|}
\hline \multirow[b]{2}{*}{ Day } & & & \multicolumn{2}{|c|}{ Volume of milk } & \multirow[b]{2}{*}{$\begin{array}{c}\text { Contrast estimates } \\
\text { p }\end{array}$} & \multirow[b]{2}{*}{$\begin{array}{l}\text { ANOVA } \\
{ }^{1} \text { Group } \\
{ }^{2} \text { Day } \\
{ }^{3} \text { Interaction }\end{array}$} \\
\hline & \multicolumn{2}{|c|}{$\begin{array}{l}\text { Mean } \\
\text { nr. of sessions }\end{array}$} & $\begin{array}{c}\text { Placebo } \\
\text { Group }(n=40)\end{array}$ & $\begin{array}{l}\text { Galactagogue } \\
\text { Group }(n=40)\end{array}$ & & \\
\hline \multirow{2}{*}{$4^{\text {th }}$} & \multirow{2}{*}{7} & $\mathrm{M} \pm \mathrm{SE}$ & $149.3 \pm 23.5$ & $203.4 \pm 26.7$ & \multirow{2}{*}{0.13} & \\
\hline & & $95 \% \mathrm{Cl}$ & $101.6-196.9$ & $149.3-257.5$ & & \\
\hline \multirow{2}{*}{$5^{\text {th }}$} & \multirow{2}{*}{7} & $\mathrm{M} \pm \mathrm{SE}$ & $233.4 \pm 23.5$ & $333.3 \pm 35.9$ & \multirow{2}{*}{0.02} & \multirow{2}{*}{$\begin{aligned} F^{1} & =5.91 \\
p^{1} & =0.017\end{aligned}$} \\
\hline & & $95 \% \mathrm{Cl}$ & $185.9-280.9$ & $260.8-405.9$ & & \\
\hline \multirow{2}{*}{$6^{\text {th }}$} & \multirow{2}{*}{7} & $\mathrm{M} \pm \mathrm{SE}$ & $325.9 \pm 28.8$ & $424.6 \pm 41.8$ & \multirow{2}{*}{0.05} & \\
\hline & & $95 \% \mathrm{Cl}$ & $267.7-384.2$ & $340.1-606.2$ & & \\
\hline \multirow{2}{*}{$7^{\text {th }}$} & \multirow{2}{*}{7} & $\mathrm{M} \pm \mathrm{SE}$ & $359.5 \pm 29.7$ & $508.6 \pm 48.2$ & \multirow{2}{*}{0.01} & \multirow{2}{*}{$\begin{array}{l}F^{2}=135.83 \\
p^{2}<0.0001\end{array}$} \\
\hline & & $95 \% \mathrm{Cl}$ & 299.4-419.6 & $411.0-606.2$ & & \\
\hline \multirow{2}{*}{$8^{\text {th }}$} & \multirow{2}{*}{7} & $\mathrm{M} \pm \mathrm{SE}$ & $398.9 \pm 32.0$ & $556.4 \pm 50.6$ & \multirow{2}{*}{0.01} & \\
\hline & & $95 \% \mathrm{Cl}$ & $334.2-463.6$ & $454.0-658.9$ & & \\
\hline \multirow{2}{*}{$9^{\text {th }}$} & \multirow{2}{*}{7} & $\mathrm{M} \pm \mathrm{SE}$ & $421.4 \pm 34.1$ & $594.3 \pm 54.0$ & \multirow{2}{*}{0.008} & \multirow{2}{*}{$\begin{array}{c}F^{3}=3.12 \\
P^{3}=0.0031\end{array}$} \\
\hline & & $95 \% \mathrm{Cl}$ & $352.5-490.4$ & $485.0-703.6$ & & \\
\hline \multirow{2}{*}{$10^{\text {th }}$} & \multirow{2}{*}{8} & $\mathrm{M} \pm \mathrm{SE}$ & $449.7 \pm 34.4$ & $579.5 \pm 48.0$ & \multirow{2}{*}{0.03} & \\
\hline & & $95 \% \mathrm{Cl}$ & $380.1-519.4$ & $482.6-676.9$ & & \\
\hline \multirow{2}{*}{$11^{\text {th }}$} & \multirow{2}{*}{7} & $\mathrm{M} \pm \mathrm{SE}$ & $469.2 \pm 37.9$ & $605.8 \pm 52.4$ & \multirow{2}{*}{0.03} & \\
\hline & & $95 \% \mathrm{Cl}$ & $392.5-545.8$ & $499.8-711.8$ & & \\
\hline
\end{tabular}

$\mathrm{M}$ - mean; $\mathrm{SE}$ - standard error; $\mathrm{Cl}$ —confidence interval; The daily volume of milk and number of expression sessions in consecutive days from 4 to 11 was indicated as a $\mathrm{M}$ with $\mathrm{SE}$ and $95 \% \mathrm{Cl}$. The difference with $\mathrm{p}$ value $<0.05$ is considered statistically significant

Group recommendations of the Dietary Guidelines for lactating women put barley malt product use as an example of good dietary praxis supporting lactation process in women [44]. Authors emphasized that barley malt and its active constituent - $\beta$-glucan are safe for use. Although allergy to barley is rare, individuals suffering from celiac disease should eliminate barley from their diet because it contains gluten. In our study safety data were collected and we showed that consumption of Femaltiker ${ }^{\oplus}$ which contains Galactagogue composition of barley malt with $\beta$-glucan and lemon balm did not cause any adverse reactions in mothers throughout study period.

\section{CONCLUSIONS}

Galactagogue composition, based on barley malt is safe and increases milk production in mothers of preterm infants.

We conclude that unique patented galactagogue formula can be safely administered in the first two weeks of lactation but the effect of the intervention on maintaining milk supply needs to be evaluated in the future studies.

\section{Acknowledgements}

All the mothers for participation of the study. Agata Serwatowska-Bargiel, Karolina Lipska-Karpinska, Nikola
Niewegłowska, Ewa Wilkos, Agnieszka Drozdowska-Szymczak, Olga Pawlik, Katarzyna Balcerek, Edyta Brala, Iwona Zalewska, Magdalena Zajac, Agnieszka Muszynska, for devotion to support mothers participate to this study.

Anna Studniczek for her dedication in office work with this clinical trial.

Nutropharma Llc for sponsoring the clinical trial. Medela Ltd. Poland for renting the lactation equipment free of charge.

\section{REFERENCES}

1. Neville MC, Morton J, Umemura S. Lactogenesis. The transition from pregnancy to lactation. Pediatr Clin North Am. 2001; 48(1): 35-52, doi: 10.1016/s0031-3955(05)70284-4, indexed in Pubmed: 11236732.

2. Weaver SR, Hernandez LL. Autocrine-paracrine regulation of the mammary gland. J Dairy Sci. 2016; 99(1): 842-853, doi: 10.3168/jds.2015-9828, indexed in Pubmed: 26299162.

3. Neville MC, Morton J. Physiology and endocrine changes underlying human lactogenesis II. J Nutr. 2001; 131(11): 3005S-8S, doi: 10.1093/jn/131.11.3005S, indexed in Pubmed: 11694636.

4. Dimitraki M, Tsikouras $P$, Manav B, et al. Evaluation of the effect of natural and emotional stress of labor on lactation and breast-feeding. Arch Gynecol Obstet. 2016; 293(2):317-328, doi: 10.1007/s00404-015-3783-1, indexed in Pubmed: 26112355.

5. Hill PD, Chatterton RT, Aldag JC. Serum prolactin in breastfeeding: state of the science. Biol Res Nurs. 1999; 1(1): 65-75, doi: 10.1177/109980049900100109, indexed in Pubmed: 11225299.

6. Sisk PM, Lovelady CA, Dillard RG, et al. Lactation counseling for mothers of very low birth weight infants: effect on maternal anxiety and infant intake of human milk. Pediatrics. 2006; 117(1): e67-e75, doi: 10.1542/peds.2005-0267, indexed in Pubmed: 16396850. 
7. Smith MM, Durkin M, Hinton VJ, et al. Initiation of breastfeeding among mothers of very low birth weight infants. Pediatrics. 2003; 111(6 Pt 1): 1337-1342, doi: 10.1542/peds.111.6.1337, indexed in Pubmed: 12777550.

8. Hartmann PE, Cregan MD, Ramsay DT, et al. Physiology of lactation in preterm mothers: initiation and maintenance. Pediatr Ann. 2003; 32(5): 351-355, doi: 10.3928/0090-4481-20030501-11, indexed in Pubmed: 12774710.

9. Hill PD, Aldag JC, Demirtas $\mathrm{H}$, et al. Association of serum prolactin and oxytocin with milk production in mothers of preterm and term infants. Biol Res Nurs. 2009; 10(4): 340-349, doi: 10.1177/1099800409331394, indexed in Pubmed: 19224938.

10. Dewey KG. Maternal and fetal stress are associated with impaired lactogenesis in humans. J Nutr. 2001; 131(11): 3012S-5S, doi: 10.1093/jn/131.11.3012S, indexed in Pubmed: 11694638.

11. Ikonen $R$, Paavilainen $E$, Helminen $M$, et al. Preterm infants' mothers' initiation and frequency of breast milk expression and exclusive use of mother's breast milk in neonatal intensive care units. J Clin Nurs. 2018; 27(3-4): e551-e558, doi: 10.1111/jocn.14093, indexed in Pubmed: 28960635.

12. Hill PD, Aldag JC, Chatterton RT, et al. Primary and secondary mediators' influence on milk output in lactating mothers of preterm and term infants. J Hum Lact. 2005; 21 (2): 138-150, doi: 10.1177/0890334405275403, indexed in Pubmed: 15886340.

13. Zanardo V, Gambina I, Begley C, et al. Psychological distress and early lactation performance in mothers of late preterm infants. Early Hum Dev. 2011; 87(4): 321-323, doi: 10.1016/j.earlhumdev.2011.01.035, indexed in Pubmed: 21316877.

14. Meier PP. Human milk and clinical outcomes in preterm infants. In: Meier PP. ed. Human milk: composition, clinical benefits and future opportunities. Vol 90. Karger Publishers, Basel 2019: 163-174.

15. Callen J, Pinelli J. A review of the literature examining the benefits and challenges, incidence and duration, and barriers to breastfeeding in preterm infants. Adv Neonatal Care. 2005; 5(2): 72-88; quiz 89, doi: 10.1016/j.adnc.2004.12.003, indexed in Pubmed: 15806448.

16. Gianni ML, Bezze EN, Sannino P, et al. Maternal views on facilitators of and barriers to breastfeeding preterm infants. BMC Pediatr. 2018; 18(1): 283, doi: 10.1186/s12887-018-1260-2, indexed in Pubmed: 30149811.

17. Brodribb W. ABM Clinical Protocol \#9: Use of galactogogues in initiating or augmenting maternal milk production, second revision 2018. Breastfeed Med. 2018; 13(5): 307-314, doi: 10.1089/bfm.2018.29092. wjb, indexed in Pubmed: 29902083.

18. Sim TF, Hattingh HL, Sherriff J, et al. The use, perceived effectiveness and safety of herbal galactagogues during breastfeeding: a qualitative study. Int J Environ Res Public Health. 2015; 12(9): 11050-11071, doi: 10.3390/ijerph120911050, indexed in Pubmed: 26371019.

19. Mortel M, Mehta SD. Systematic review of the efficacy of herbal galactogogues. J Hum Lact. 2013; 29(2): 154-162, doi: 10.1177/0890334413477243, indexed in Pubmed: 23468043.

20. Anderson PO. Herbal use during breastfeeding. Breastfeed Med. 2017; 12(9): 507-509, doi: 10.1089/bfm.2017.0150, indexed in Pubmed: 28926284.

21. Gupta M, Abu-Ghannam N, Gallaghar E. Barley for brewing: characteristic changes during malting, brewing and applications of its by-products. Comprehensive Reviews in Food Science and Food Safety. 2010; 9(3): 318-328, doi: 10.1111/j.1541-4337.2010.00112.x.

22. Mennella JA, Beauchamp GK. Beer, breast feeding, and folklore. Dev Psychobiol. 1993; 26(8): 459-466, doi: 10.1002/dev.420260804, indexed in Pubmed: 8293892

23. Carlson HE, Wasser HL, Reidelberger RD. Beer-induced prolactin secretion: a clinical and laboratory study of the role of salsolinol. J Clin Endocrinol Metab. 1985; 60(4): 673-677, doi: 10.1210/jcem-60-4-673, indexed in Pubmed: 3972968.

24. Sawagado L, Houdebine LM. Identification of the lactogenic compound present in beer. Ann Biol Clin (Paris). 1988; 46(2): 129-134, indexed in Pubmed: 3382062.

25. Sawadogo L, Sepehri H, Houdebine LM. [Evidence for a stimulating factor of prolactin and growth hormone secretion present in brewery draff] [Article in French] . Reprod Nutr Dev. 1989; 29(2): 139-146, indexed in Pubmed: 2502999.
26. Nehring-Gugulska M, Kucia M, Wietrak E. Stymulacja laktacji z wykorzystaniem słodu jęczmiennego a parametry wzrostowe dziecka w przypadku kryzysu laktacyjnego. Położ Nauka Prakt. 2015; 1(29): 34-38.

27. Fewtrell MS, Lucas $P$, Collier $S$, et al. Randomized trial comparing the efficacy of a novel manual breast pump with a standard electric breast pump in mothers who delivered preterm infants. Pediatrics. 2001; 107(6): 1291-1297, doi: 10.1542/peds.107.6.1291, indexed in Pubmed: 11389245.

28. Balogun OO, Dagvadorj A, Anigo KM, et al. Factors influencing breastfeeding exclusivity during the first 6 months of life in developing countries: a quantitative and qualitative systematic review. Matern Child Nutr. 2015; 11(4): 433-451, doi: $10.1111 / \mathrm{mcn} .12180$, indexed in Pubmed: 25857205.

29. Gatti L. Maternal perceptions of insufficient milk supply in breastfeeding. J Nurs Scholarsh. 2008; 40(4): 355-363, doi: 10.1111/j.1547-5069.2008.0 0234.x, indexed in Pubmed: 19094151.

30. Abrams SA, Schanler RJ, Lee ML, et al. Greater mortality and morbidity in extremely preterm infants fed a diet containing cow milk protein products. Breastfeed Med. 2014; 9(6): 281-285, doi: 10.1089/bfm.2014.0024, indexed in Pubmed: 24867268.

31. Cristofalo EA, Schanler RJ, Blanco $C L$, et al. Randomized trial of exclusive human milk versus preterm formula diets in extremely premature infants. J Pediatr. 2013; 163(6): 1592-1595.e1, doi: 10.1016/j. jpeds.2013.07.011, indexed in Pubmed: 23968744.

32. Lau C. Breastfeeding challenges and the preterm mother-infant dyad: a conceptual model. Breastfeed Med. 2018; 13(1): 8-17, doi: 10.1089/bfm.2016.0206, indexed in Pubmed: 29048210.

33. Meier PP, Johnson TJ, Patel AL, et al. Evidence-based methods that promote human milk feeding of preterm infants: an expert review. Clin Perinatol. 2017; 44(1): 1-22, doi: 10.1016/j.clp.2016.11.005, indexed in Pubmed: 28159199.

34. Khan TM, Wu DBC, Dolzhenko AV. Effectiveness of fenugreek as a galactagogue: a network meta-analysis. Phytother Res. 2018; 32(3): 402-412, doi: 10.1002/ptr.5972, indexed in Pubmed: 29193352.

35. Zecca E, Zuppa AA, D'Antuono A, et al. Efficacy of a galactogogue containing silymarin-phosphatidylserine and galega in mothers of preterm infants: a randomized controlled trial. Eur J Clin Nutr. 2016; 70(10): 1151-1154, doi: 10.1038/ejcn.2016.86, indexed in Pubmed: 27245206.

36. Serrao F, Corsello M, Romagnoli C, et al. The long-term efficacy of a galactagogue containing sylimarin-phosphatidylserine and galega on milk production of mothers of preterm infants. Breastfeed Med. 2018; 13(1): 67-69, doi: 10.1089/bfm.2017.0169, indexed in Pubmed: 29148822.

37. Hill PD, Aldag JC. Milk volume on day 4 and income predictive of lactation adequacy at 6 weeks of mothers of nonnursing preterm infants. J Perinat Neonatal Nurs. 2005; 19(3): 273-282, doi: 10.1097/00005237-20050700000014, indexed in Pubmed: 16106236.

38. Hoban R, Bigger $\mathrm{H}$, Schoeny M, et al. Milk volume at 2 weeks predicts mother's own milk feeding at neonatal intensive care unit discharge for very low birthweight infants. Breastfeed Med. 2018; 13(2): 135-141, doi: 10.1089/bfm.2017.0159, indexed in Pubmed: 29377728.

39. Amir LH. Breastfeeding - managing, supply'difficulties. Aust Fam Physician. 2006; 35(9): 686-689, indexed in Pubmed: 16969436.

40. Dougherty $D$, Luther $M$. Birth to breast - a feeding care map for the NICU: helping the extremely low birth weight infant navigate the course. Neonatal Netw. 2008; 27(6): 371-377, doi: 10.1891/0730-0832.27.6.371, indexed in Pubmed: 19065966.

41. Hill PD, Aldag JC, Chatterton RT, et al. Effects of pumping style on milk production in mothers of non-nursing preterm infants. J Hum Lact. 1999; 15(3): 209-216, doi: 10.1177/089033449901500310, indexed in Pubmed: 10578798.

42. Becker GE, Smith HA, Cooney F, et al. Methods of milk expression for lactating women. Cochrane Database Syst Rev. 2011; 9(12): CD006170, doi: 10.1002/14651858.CD006170.pub3, indexed in Pubmed: 22161398.

43. Nehring-Gugulska M, Żukowska-Rubik M. Niedostateczny przyrost masy u dziecka karmionego wyłącznie piersią — diagnoza, postępowanie, stymulacja laktacji. Post Neonatol. 2014; 2(21): 43-55.

44. Borszewska-Kornacka MK, Rachtan-Janicka J, Wesołowska A, et al. Stanowisko Grupy Ekspertów w sprawie zaleceń żywieniowych dla kobiet w okresie laktacji. Stand Med Pediatr. 2013; 10: 265-279. 